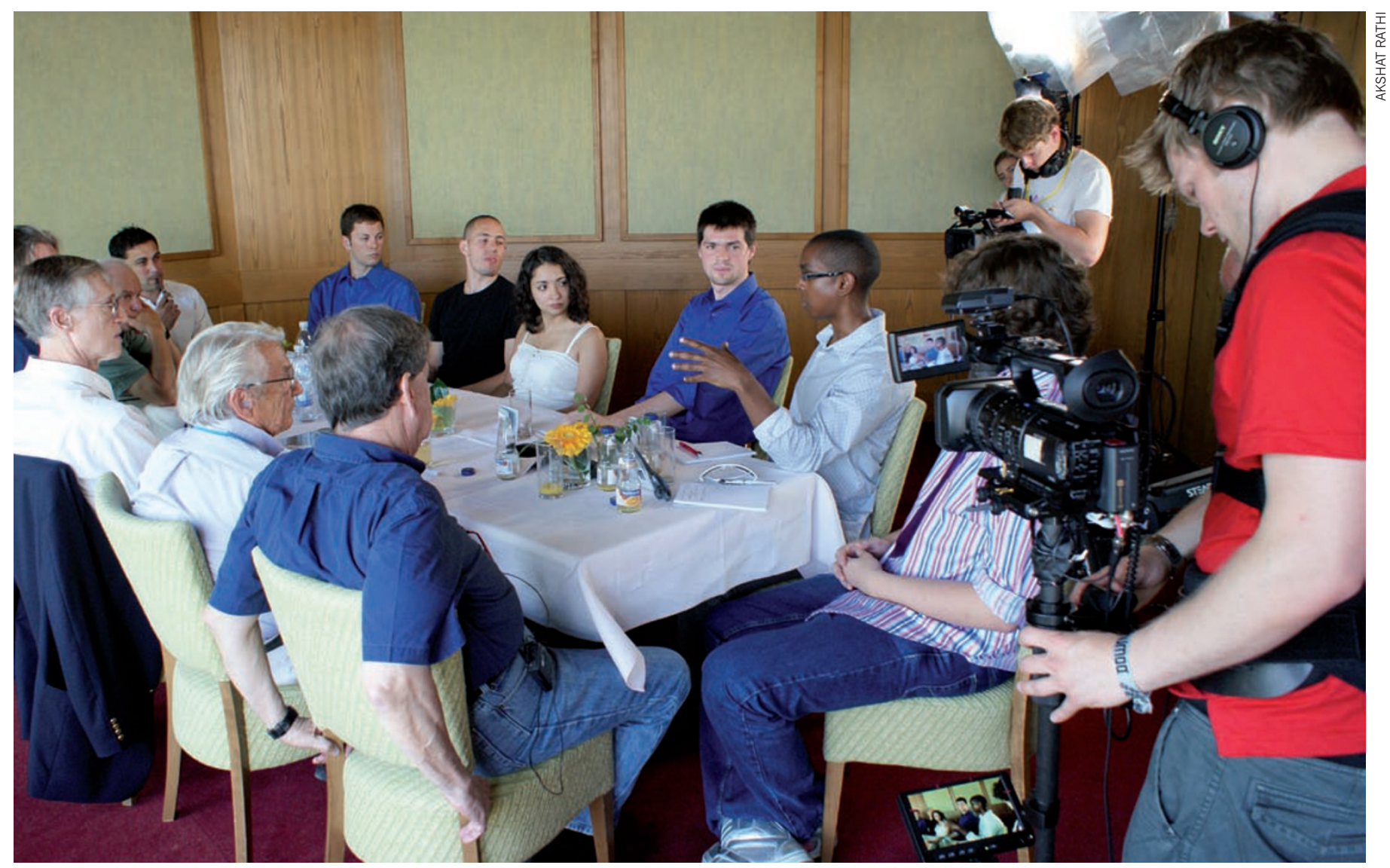

\title{
Turning the tables
}

\section{What happens when the spotlight shines on the young scientists?}

\section{BY AKSHAT RATHI}

$\mathrm{T}$ he annual Lindau Nobel Laureate Meeting is the opportunity for a select few hundred young scientists from around the world to mingle with some of today's most celebrated scientists. The main goal of the meeting is to give students an opportunity to interact with their scientific idols, quiz them about their lives and learn about research from a wider perspective.

In addition to lectures given by the Nobel laureates, there are private, closed-door sessions and many informal, social events. Yet, until now, there has been one form of interaction that did not get adequate attention: a chance for the laureates to learn more about the students and their views of science. Turning the Tables aims to change that.

In Turning the Tables, the 'expert panel' comprised students representing all branches of science and many parts of the world. The 'audience' consisted of five Nobel laureates, carefully chosen to reflect the broadest and most enquiring minds - able to put the panel through its paces.

This was not an easy event to chair. As the moderator, Adam Rutherford of Nature Publishing Group, addressed the laureates: "My job is to stop you guys from talking to each other and make sure that you ask the panel penetrating questions so that you can learn more about them."

So what questions did the Nobelists ask?

\section{Advice to laureates}

- Reply to emails from students within twelve hours

- Don't dictate a student's life

- Give creative freedom

- Foster relationship among students in the lab, not just with them

- Let students develop their 'voice' when writing papers

- Communicate your science to the public by using the media
And how did the young scientists respond? Here is a snapshot of the session.

\section{LABORATORY ETIQUETTE}

Hinting, perhaps, at the no-holds-barred tone of this session, the first topic proposed by Rutherford concerned the controversial comments of a prominent scientist who had recently described $\mathrm{PhD}$ students working in the laboratory as "serfs". Was this accurate or, indeed, proper?

Most of the panellists disputed the statement, but there was one supporter. "I don't think I have any illusions. I am proud to be a serf. I am proud to be a labourer of science," said Baybers Kuelebi, a Turkish student finishing his $\mathrm{PhD}$ in astrophysics at Heidelberg in Germany. "In my case, my supervisor is [the one] delegating work and I do the research, write the codes and write the papers. In that respect, from the labour point of view, we are serfs."

Evans Boney, who is pursuing his $\mathrm{PhD}$ in theoretical chemistry at the California Institute of Technology under the supervision of Nobel 
laureate Rudolph Marcus, acknowledged some truth to the statement but said personal initiative could make a difference. He makes himself "rise to the occasion" whenever he meets with Marcus, so that he does not "sound like a student".

\section{RELATIONSHIP WITH SUPERVISOR}

A lot depends on the relationship that a supervisor fosters with their graduate students. "What kind of relationship should a supervisor have with his students?" asked Rutherford. Benyam Kinde, a first year student in the Harvard-MIT MD-PhD programme, said he has enjoyed a "collegial" relationship with his supervisor, even when he was an undergraduate, and that has allowed him to be creative.

This relationship, however, should be close but not too close - to allow the individuality of the student to develop, said Harold Kroto, a winner of the 1996 Nobel Prize in Chemistry.

In addition, graduate students, whether serfs or recognised as equals, all need quality time with their supervisors. Yet Nobel laureates who supervise students travel widely to visit collaborators and give talks around the world, leaving little time for students. Boney admitted he has to deal with the travelling issue and had not been prepared for it. His advice was to plan ahead. "As long as I ask in advance, like a couple of months, it is fine", he added.

George Smoot, who shared the Nobel Prize in Physics in 2006, admitted that he travels a lot and occasionally supervises students "who want their hand held". But he felt that to best prepare students to become independent researchers they should try and do as much as they can themselves to get to the point where "they don't know why you're their mentor."

\section{SCIENCE WORLDWIDE}

Smoot observed that most of the students on the panel were pursuing their scientific career in a foreign country, and asked why.

The panel explained that this sort of relocation had many reasons: a lack of facilities in their home country; an increased need for specialisation in science; or a need to do multiple postdoctoral appointments to secure an academic position.

Inna Pertsovskaya was a full-time teacher in a Russian state school while she was doing her $\mathrm{PhD}$. It was a commitment of nine hours per day, three days a week. "I did not have patience for those teenagers as well as take care of my daughter in the evenings," she admitted. The situation has improved since she moved to Spain to continue her studies, and she is now a $\mathrm{PhD}$ student in neuroimmunology at the University of Barcelona.

Aaron Ciechanover, who shared the Nobel Prize in Chemistry 2004, wondered whether these foreign pursuits were causing a brain drain in their respective home countries, for example in Turkey, in the case of Kulebi, and
Russia, for Pertsovskaya.

Kulebi agreed that this wandering can become permanent. "After some time we become stateless and are ready to move anywhere to do what we really want to do, but then you cannot really settle.'

\section{IDEALISM AND CYNICISM}

The most contentious issue for most of the panel did not concern their day-to-day work, but its wider context. "What are you guys most concerned about right now?" asked Smoot. Kinde replied: "My biggest concern is outside of science. It's the people who have a lot of influence on science: the politicians. There should be more politicians who have been scientists before." Kroto responded: "There is a conflict between the scientific way of thinking and politics - which is dogma. Science is not [dogmatic] and that is why I feel that there are not as many really good scientists in politics."

Smoot distilled the issue, "We see two sides here: the idealism of youth and the cynicism of the old. I think that idealism is great but

\section{Advice to students}

- Choose a supervisor who does not travel too much

- Don't try to please your supervisor all the time, be prepared to challenge them

- Put questions to your supervisor, but think of some possible suggestions beforehand

- Assume your supervisor is wrong and develop your own way to approach the problem

- Idealism regarding science in politics is good, but be aware that it will be a steep challenge

- Don't give up too easily

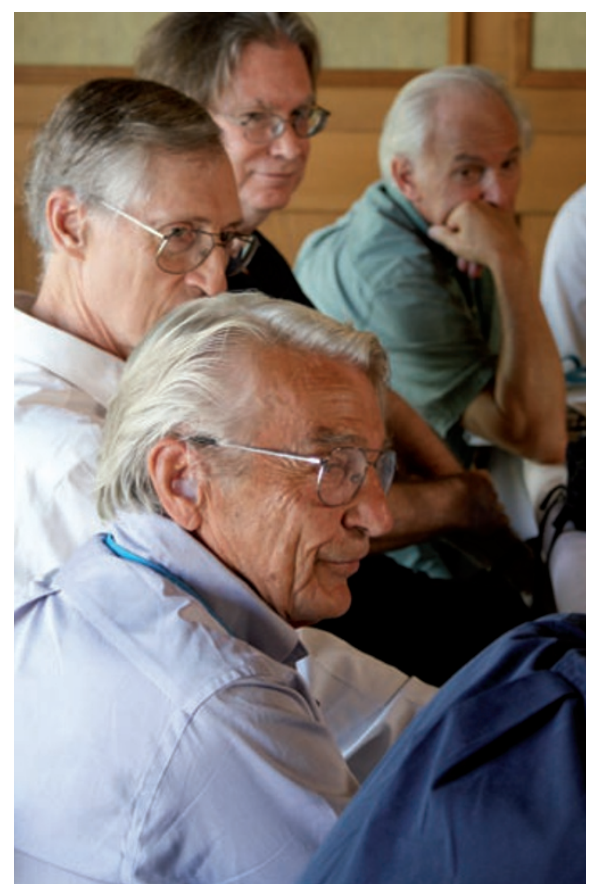

in the real world it is a bit of mixture... If the students can persuade the people then eventually they [the people] will make the right decision." He urged the students not to be cynical: "You do have the opportunity. You can have your own blog on the internet. You can express your views clearly and some blogs are very influential.'

Winning a Nobel prize provides perhaps the best chance for a scientist to influence politics and cultural perception of science. Should that not provide optimism? Mather agreed: "I think the interaction of science and politics is really important and I use a part of my Nobel prize money to give summer internships to physics students to work with politicians in Washington DC."

With the credibility and authority of the scientific community arguably having taken a hit after 'climategate', the Nobelists turned to the students for help. "Specifically in the case of climate change, we see a massive political backlash because they [politicians] do not understand how science works," said Kroto. "That's why it is important that students like you get involved [in science communication] as much as you can."

Yet the panel were sceptical that these messages would be heard: in many countries the current education system does not allow children to learn the skills of critical thinking. "There is a declining population of highschool science graduates in the United States," Boney bemoaned. "Thus, there is a decline in the population that will understand the science we try to teach. It is hard to work with such a basic disconnect."

\section{LESSONS LEARNED}

Even with years of experience of supervising graduate students, in the brief Turning the Tables session, the Nobel laureates still learnt new things about how young scientists think and about what is important to them. And the students were not shy about offering advice (see Advice to laureates).

The laureates understood the students' positions. As Smoot said: "People [young scientists] not only want to know how things work but they also want their work to be important - to go out and help the world."

However, the laureates were not without their own advice (see Advice to students). They appreciate that today's young scientists need to work harder to establish themselves than they had to work in their times. Ciechanover concluded, "We shouldn't burden them too much. We heard they have to deal with a lot of basic problems. [But despite these problems] it is important not be cynical and be aware of the many interfaces between science and society."
Akshat Rathi is a DPhil student at the University of Oxford and blogger for the Lindau meetings $\rightarrow$ NATURE.COM

for a video of the event go.nature.com/RS89tX 